\title{
THE RELATIONSHIP BETWEEN LEADERSHIP STYLE AND HOSPITAL EMPLOYEE ENGAGEMENT IN PAPUA NEW GUINEA
}

\author{
Grant Robert Muddle \\ Papua New Guinea National Department of Health \\ Correspondence: grantmuddle@malyshka.com.au
}

\begin{abstract}
Engagement, an important concept in the determination of overall employee output, has become an important factor within the healthcare sector, and in light of various challenges facing employees, such as high workloads and long working hours, engagement also plays a significant role in ensuring improved healthcare output. Meanwhile, leadership, which plays a major role in guiding and influencing employees toward goal achievement, is the driving force behind employee engagement. Accordingly, the purpose of this study was to examine the nature of the relationship between three different leadership techniques -transformational, transactional and passive avoidant-and employee engagement in the Papua New Guinea (PNG) healthcare sector. Research has shown that transactional and transformational leadership have the highest level of impact on employee engagement as a result of the role leaders play in the inspiration and stimulation of employees. The methodology applied to examine this statement involved a random selection of 84 health employees from three PNG hospitals: ANGAU Memorial Provincial Hospital, Mount Hagen General Hospital and Port Moresby General Hospital. A correlation analysis of the quantitative research methodology was then applied to evaluate the relationship between key variables in the collected data. A final analysis of results revealed that, within the PNG healthcare sector, transformational and transactional leadership both have a positive relationship with employee engagement, while passive avoidant leadership has a negative relationship with employee engagement.
\end{abstract}

\section{KEYWORDS}

Employee Engagement; Transformational Leadership; Transactional Leadership; Passive Avoidant Leadership; Change Management; Effective Leadership; Patient Care

\section{INTRODUCTION}

\section{BACKGROUND}

Adequate healthcare service delivery is often hampered by factors such as poor management and resource provision. [1] For developing countries, inadequate healthcare service delivery is usually a direct consequence of unequal resource distribution, which in turn leads to healthcare institutions experiencing a lack of access to sufficient resources and funding. [2] These challenges then lead to increased employee turnover as a result of the combined effects of reduced employee satisfaction, low motivation and burnout from the increased workload stemming from a high patient-to-physician ratio. [3] As such, the quality of healthcare services provided by affected healthcare workers is reduced, adversely affecting patient outcomes.

In the developing country of Papua New Guinea (PNG), population 7.4 million, an examination of the healthcare sector clearly illustrates inadequate healthcare service delivery as a result of unequal resource distribution. All healthcare centres and aid posts each serve a population between 3,000 and 20,000 , with $80 \%$ of demand for healthcare coming from rural areas, which contain a 
majority of PNG's population. [4] However, although PNG has experienced an increasing demand for healthcare services due to rapid annual population growth, limited access to sufficient healthcare services continues to be a major issue given the inadequate resource distribution and fund allocation. [5] Low patient outcomes, as a direct result of these challenges, can be attributed to reduced employee motivation, satisfaction and motivation.

Consequently, employee engagement_through the level of motivation, satisfaction and commitment emotionally displayed by employees towards organisational goal achievement-plays a significant role in determining health worker output in the face of the above challenges. [6] Employee engagement level is also influenced by factors such as work environment, team organisation and pay in such a way that poor working environment, poor team organisation and insufficient pay directly yields reduced levels of motivation, satisfaction and commitment, which in turn leads to reduced engagement levels among employees. Consequently, the level of employee engagement is therefore significantly associated with the leadership style being utilisedtransformational, transactional or passive avoidant-where higher engagement levels are observed due to effective leadership styles, but ineffective styles result in lower engagement levels. [7]

Each leadership style has distinct characterisations. Whereas passive avoidant leadership involves intentional avoidance of employee management, both transactional and transformational leadership comparatively involve a higher level of leader-follower interaction. More specifically, passive avoidant leadership entails the absence of active involvement in employee organisation and management owing to the intentional neglect of behaviour which is oriented towards leadership. [7] As a result, this lack of involvement makes passive avoidant leadership unsuitable for application within the high-stress environment within the health care sector, which introduces the necessity for increased leader-follower interaction for the purpose of maintaining high employee output.

Transactional leadership revolves around management based on the contingency reward system, which involves reward provision upon the portrayal of employee effort. The contingency reward system is used to complement the exception-based management model applied for this leadership technique, whereby while rewards are provided based on the achievement of high output by employees, low output results in punishment, which may be issued in the form of salary bonus cuts and reduced work break periods. [8] Transactional leadership is further divided into two main forms: transactional active and transactional passive. Whereas transactional active leadership involves active monitoring of workers and immediate response to identified issues, transactional passive leadership only features leader intervention upon the occurrence of issues requiring immediate intervention. [8] As such, the contingency reward system therefore acts as a motivator towards highquality output by employees through providing salary bonuses, promotions or other rewards for high effort.

Finally, transformational leadership involves constant leader-follower interactions with the aim of achieving set goals. Through transformational leadership, leaders use techniques such as charisma, employee motivation and intellectual stimulation to ensure a high output quality is achieved and maintained, even without contingency rewards. [8] More specifically, motivation and intellectual stimulation result in employee inspiration towards the achievement of set goals and objectives, in a way which ensures high levels of output regardless of various issues within the internal and externa work environment. Consequently, the characterisations of transformational leadership, through their encouragement of employee satisfaction, commitment and motivation, have significant levels of impact on employee engagement levels, especially amid high-stress working conditions in the health sector. As such, this makes transformational leadership suitable for application within the health sector with the aim of maintaining high levels of output.

Nevertheless, despite the significant effect of leadership on employee engagement, most current literature ignores employee engagement among healthcare workers in lowto-middle-income countries, creating a literature gap. [9] The need to investigate healthcare employee engagement within such countries stems from the existence of various limitations facing the health sector due to insufficient resource distribution, highlighting the need to investigate the most effective leadership techniques for enhancing engagement levels and, ultimately, patient outcomes. Accordingly, this study aims to fill this literature gap via a quantitative methodology investigating the relationship between three leadership stylestransformational, transactional and passive avoidant-and employee engagement in the PNG health sector. 
In this light, three major hospitals-Port Moresby General Hospital, Mount Hagen General Hospital and ANGAU Memorial Provincial Hospital-were used for the examination of the impact of leadership styles on employee engagement in the PNG health sector.

FIGURE 1: A GEOGRAPHICAL MAP OF THE LOCATION OF PORT MORESBY GENERAL HOSPITAL (RED) MOUNT HAGEN GENERAL HOSPITAL (BLACK) AND ANGAU MEMORIAL PROVINCIAL HOSPITAL (BLUE)

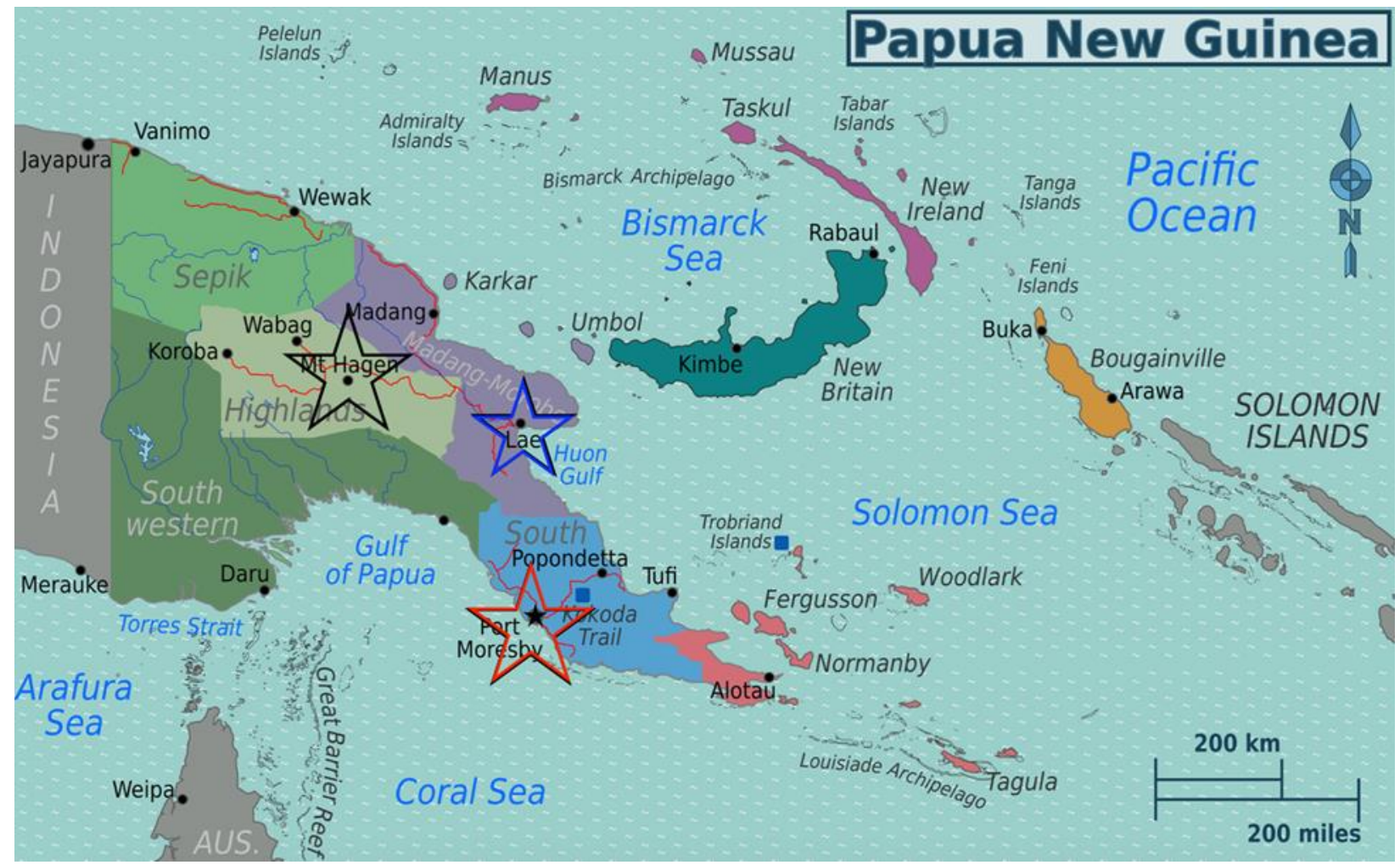

Port Moresby General Hospital(PMGH), which has a 1012 bed-count and a 1600 staff-count, is the largest PNG hospital. Furthermore, its large patient capacity in addition to its access to superior medical equipment compared to other hospitals within PNG facilitated the establishment of its status as the National Referral Hospital. According to Ambang [10], its administration structure consists of a number of appointed directors - Director of Corporate Services, Director of Nursing and the Director of Medical Health Services, who answer to the overall head of operations and management, the CEO. [10] ANGAU Memorial Provincial Hospital, which has a 900 staff-count and a total of 800 beds, is the second largest hospital in PNG. Its administrative structure bears a high level of similarity to that of PMGH, and consists of a group of directors who answer to a CEO. In addition, Chiefs of Department are appointed to reside over the operations within all medical specialties. Mount Hagen General Hospital is the third largest hospital in PNG. It has a 400 staffcount and a total of 250 beds for gynaecology, obstetrics, paediatrics, surgery and medical patients. As compared to the other two hospitals, Mt Hagen has a different administrative structure, which consists of a group of managers-the Hotel Services, Finance, HR, Transport and Maintenance managers, as well as directors-the Nursing and Medical Services Directors who answer to the Hospital Manager. In addition, all medical specialties have Chiefs of Departments who are in charge of their operational and technical management and organisation.

Regardless of the differences in administrative structure, all three hospitals encounter similar issues such as poor investment in medical infrastructure and lack of sufficient manpower to cater for the existing high health care demand. [10] In order to solve this issue, the PNG national government developed a new National Health Plan, which would enable the improvement of medical resource distribution through the combination of all health care institutions under the Provincial Health Authority banner. [10] However, in spite of these efforts, the PNG heath sector is still characterised by issues such as workforce demotivation, technical skill maldistribution and high numbers of advanced age health workers as opposed to younger employees. In this light, this study aims at examining the impact of leadership techniques on employee engagement levels in the face of such issues, for 
the purpose of facilitating the overall improvement of patient outcomes as a result of improved health worker output. For the outline of this examination, this paper structure features literature review, methodology, results and discussion sections, which provide a detailed window into the analysis and conclusions provided by data collected during the course of this study.

\section{LITERATURE REVIEW}

The PNG health care sector faces issues such as low numbers of health workers based on the health care supply-demand ratio, as well as poor medical resource and technical skill distribution. [4] Consequently, these issues in turn result in the low employee engagement levels owing to the resulting work strain associated with high patient to physician ratios and insufficient medical resources and equipment to adequately support the demand for health care, especially in rural areas. In this case, the implementation of effective leadership techniques becomes necessary for the establishment and maintenance of high levels of employee engagement in spite of all the existing challenges within the PNG health sector. As such, this study provides a critical analysis of the effect of three leadership techniques-transformational, transactional and passive avoidant-on employee engagement within the PNG health sector, with the aim of facilitating the overall improvement of employee output regardless of the various challenges which have been identified.

According to Chaudhry and Javed [8], passive avoidant leadership is a technique which features the intentional avoidance of employee management by leaders. Consequently, this bears the implication of an absence of provision of management directions by leaders during the implementation of this leadership technique. Intentional avoidance of management in turn leads to the intentional neglect of behaviour which is leadership-oriented, thus resulting in extremely low levels of leader-follower interaction. [1 1] As a result, the low level of leader-follower interaction portrayed by passive avoidant leadership makes this technique unsuitable for implementation within the health sector, which features a high level of reliance on such interactions for the maintenance of a smooth flow of operations.

Transactional leadership involves the use of a contingency reward-punishment system to complement the exceptionbased management model which implies leader involvement in employee management only upon the condition that employee output is provided in return, with high output levels being rewarded with rewards such as salary bonuses and promotions. Xenikou [12] supports this by highlighting the two major transactional leadership characteristics as exception-based management and contingent reward, whereby the provision of rewards based on good performance is combined with the conservative resource application upon the need for unexpected event resolution. Upon the consideration of these two characteristics which apply to the two forms of transactional active and transactional passive leadership, the general transactional leadership technique can be categorised as a model which is based on defensive management. As such, although the contingency reward system may be associated with improved levels of employee motivation, transactional leadership may also lead to low levels of employee satisfaction as a result of exception-based management which leads to low levels of leader-follower interaction. Consequently, this implies transactional leadership would yield low levels of suitability for application within the health sector owing to its adverse effects on job satisfaction, which in turn directly affects employee engagement levels.

Compared to transactional and passive avoidant leadership, transformational leadership features the highest levels of leader-follower interaction. Transformational leadership involves the application of motivation and intellection stimulation for the purpose of improving employee commitment and satisfaction with the aim of improving overall engagement levels. This leadership technique consists of four major dimensions-inspiration based on motivation, individualized consideration, stimulation of an intellectual thinking processes and idealized influence. [13] Whereas consideration is enacted through listening and response to the needs of followers by leaders, inspirational motivation is enacted through the constant application of employee motivation efforts by leaders. Comparatively, idealised influence features the development of high leader-follower trust levels, while intellectual stimulation revolves around the honing of follower problem solving skills through improving the overall level of problem identification and awareness.

Effective utilisation of these four dimensions facilitates the establishment of the role model status of leaders within organisations, thus helping the improvement of follower productiveness and success. Transformational leadership therefore leads to the association of leaders with high passion, energy and visibility within their designated 
working environments, which in turn enables the development of effective communication and problem solution among employees. Consequently, this yields increased levels of follower empowerment and motivation as a result of the establishment of communal-based approach to organisational management, which in turn leads to high levels of employee engagement in general, thus making transformational leadership suitable for application within the high-stress working environment associated with the health sector.

Examination of the characteristics of each of the three leadership techniques is therefore important for the determination of their potential effect on employee engagement. As stated by Hutchinson \& Jackson [14], the effectiveness of nurse leadership is a significant determinant of the achievement of optimum patient outcomes. As such, identification of effective leadership techniques is important owing to its ability to aid the avoidance of implementation of ineffective leadership techniques which would adversely affect patient outcomes as a direct result of low health worker output. [6] Effective leadership technique identification is therefore important for not only facilitating professional development within the health sector, but also enabling better leadership skill development in addition to flexibility and adaptability with the aim of improving decision making and strategy development abilities.

Effective leadership technique implementation yields improved health worker engagement levels, which will in turn yield improved patient outcomes as a direct result of improved health worker commitment, satisfaction and motivation. In spite of the established importance of effective leadership techniques in the improvement of employee output, a research gap which features a lack of sufficient analysis of the implementation of effective leadership in the PNG health sector, has been identified. [13] In this light, the analysis of the effect of leadership techniques on employee engagement provided by this study will thus enable the closure of this research gap through the selection of effective leadership techniques to enable the improvement of employee engagement levels within the PNG health sector, which will also enable the overall improvement of the quality of health care service provision.

\section{RESEARCH QUESTIONS}

To achieve the study purpose, three research questions were utilised:

- RQ1: Is there a positive relationship between transformational leadership behaviours and employee engagement among healthcare workers

- $R Q 2:$ Is there a positive relationship between transactional leadership behaviours and employee engagement among healthcare workers?

- $\quad$ RQ3: Is there a positive relationship between passive avoidant leadership behaviours and employee engagement among healthcare workers?

\section{METHODS}

\section{STUDY CONTEXT AND SETTING}

For this study context, a quantitative research methodology was applied since it allowed for conducting further analytical studies based on the research findings. [15] More specifically, a correlational study design was used to analyse the relationship between employee engagement and leadership, through the collection of data from responses provided in questionnaires to determine the degree of correlation between dualistic variables. [16] The variables analysed were transformational leadership, transactional leadership, passive avoidant leadership and employee engagement. Based on research questions and the purpose statement, determining the independent and dependent variables facilitated the application of correlation analysis.

\section{POPULATION}

The target population was 84 health employees randomly selected from an ID employee group of volunteers comprising nursing officers, allied health workers, nurses, doctors and health extension officers. Three hospitals-Port Moresby General Hospital, Mount Hagen General Hospital and ANGAU Memorial Provincial Hospital-were identified for the population sample selection, whereby 28 volunteer employees were selected from each hospital according to the aforementioned specifications.

\section{Sampling strategy}

Assumptions based on the Pearson correlation model were used to determine the sampling strategy. [17] These assumptions included approximate normal data distribution, rough inter-variable linear association and absence of significant outliers within the model. [18] As 
such, G-power was utilised for the computation of the sample size required to calculate the Pearson correlation; a 0.3 correlation coefficient, 0.8 statistical power threshold and 0.05 alpha level were selected. The overall determination of the sample size was based on the analysis of the G-Power output, which was computed after the selection of the aforementioned values of the correlation coefficient, alpha level and statistical power threshold. This analysis aided the setting of the optimum population sample at 84 with regard to the given parameters in order to facilitate the overall accuracy of data collected. The selected population sample was equally divided among the identified ID group of volunteer employees within three institutions selected for analysis, with the aim of providing equal grounds for the analysis of impact of the three leadership techniques on employee engagement based on the examination of all individual responses.

\section{Study variables}

Variables included employee engagement, transformational leadership, transactional leadership and laissez-faire leadership. A positive correlation was identified if employee engagement increased with an increased utilisation of any of the three leadership styles in the identified healthcare institutions. Otherwise, a negative correlation was identified.

\section{Data collection procedure and instruments}

IRB approval and study permission were obtained before research began, according to ethical considerations. Ethical considerations included: submission of necessary research forms for IRB approval, seeking of approval from the chairman and chief executive officers before commencement of the study, ensuring that participants were informed of their anonymity and the voluntary nature of the study and the use of a two-factor authentication password protected computer to ensure the safety of participant information after the study. During the study, two questionnaires_the MLQ_5X and the Gallup Q12 survey form-were administered after return of informed consent forms by each of the 84 participants. These questionnaires featured survey questions which according to Avolio and Bass [19], play a significant role as useful leadership measurement tools for the effectiveness of the various leadership techniques identified for this study. This effectiveness is facilitated by the design of these survey questions, which enable them to accurately determine the level of employee satisfaction, commitment and engagement through the use of a five-point Likert scale which is attached to all respective responses. Demographic variables (division, age group, years of experience, department and gender) were also collected, in addition to leadership and employee engagement data. Afterwards, participant responses were collected and stored in a laptop with a two-factor authentication security password. This whole data collection process took place over a period of three days at each of the selected institutions, thus giving a total of nine days for the whole data collection period. The expected valid response rate for this study was set at $95 \%$.

\section{Analysis methods}

Descriptive and inferential statistics were used for data analysis. Descriptive statistics were used to illustrate numerical data in a summarised, precise and organised format, through measures such as standard deviations, percentages and mean values. [20] Inferential statistics, on the other hand, utilised a general linear model and correlation tests for data analysis in order to examine the relationship between employee engagement and leadership styles, based on collected data. [21] Reliability tests for the data collected from the MLQ_5X and Gallup Q12 questionnaires used were based on the 0.74 to 0.94 reliability range reported by Bass and Avolio [22] after conducting a study using a large $(\mathrm{N}=1394)$ data set. More specifically, the Cronbach's Alpha Coefficient for reliability yielded a 0.93-0.72 and 0.58-0.78 range for transformational and transactional leadership respectively, while for passive avoidant leadership, it yielded a 0.72-0.49 range.

\section{RESULTS}

\section{GENERAL VARIABLES FOR EACH HOSPITAL}

Referring to Table 1 below, the most frequently occurring age groups within the sample population were 29-39 and 40-50 years with 5-10 and 15-20 years of experience being recorded for most of the population, which mostly belonged to the female gender. In addition, while Nursing division had the overall highest occurrence frequency, followed by the doctor, Allied Health and Support Service divisions, Registered Nurse and Back of House were the departments with the highest occurrence frequency within the sample population. This has been illustrated in Table 1 below. 
AGE

$18-28$ 5

29-39

$40-50$

51-60

10

11.90

61-65

1

1.19

\section{GENDER}

FEMALE

\section{DIVISION}

\begin{tabular}{|c|c|c|}
\hline ALLIED HEALTH & 20 & 23.81 \\
\hline DOCTOR & 20 & 23.81 \\
\hline NURSING & 24 & 28.57 \\
\hline SUPPORT SERVICES & 20 & 23.81 \\
\hline \multicolumn{3}{|l|}{ DEPARTMENT } \\
\hline BACK OF HOUSE & 13 & 15.48 \\
\hline HEALTH EXTENSION OFFICER & 2 & 2.38 \\
\hline HOTEL SERVICES & 7 & 8.33 \\
\hline IMAGING & 2 & 2.38 \\
\hline LABORATORY & 6 & 7.14 \\
\hline MIDWIFE & 5 & 5.95 \\
\hline OTHER & 2 & 2.38 \\
\hline PATHOLOGY & 2 & 2.38 \\
\hline PHYSIOTHERAPY & 4 & 4.76 \\
\hline RADIOLOGY & 5 & 5.95 \\
\hline REGISTERED NURSE & 18 & 21.43 \\
\hline REGISTRAR & 7 & 8.33 \\
\hline RESIDENT & 3 & 3.57 \\
\hline SENIOR MEDICAL OFFICER (SMO) & 8 & 9.52 \\
\hline
\end{tabular}




\section{YEARS OF EXPERIENCE}

LESS THAN 5

5-9

$10-14$

15-19

$20+$
4

23

18

22

17
21.43

4.76

27.38

26.19

20.24

Note. Due to rounding errors, percentages may not equal $100 \%$.

\section{TRANSFORMATIONAL LEADERSHIP}

As seen in Table 2 below, Transformational leadership had the highest overall Q12_mean, maximum and minimum in Hospital 1, while Hospital 2 and 3, although to a lower extent, also recorded high Q12_mean values for this leadership style

In Table 3 below, Inspirational Motivation, Idealised Behaviours and Idealised Attributes the highest mean values, thus identifying them as the most desirable transformational leadership traits.
Transformational leadership had the highest Pearson Correlation Matrix among the three leadership styles being studied. This can be seen in Table 4 below.

Finally, compared to transactional and passive avoidant leadership, transformational leadership had the highest Variance Inflation Factor (VIF) and Linear Regression Coefficients as illustrated by Table 5 and 6 below.

TABLE 2. MEAN (M), STANDARD DEVIATION (SD), SAMPLE SIZE (N), MINIMUM (MIN), MAXIMUM (MAX), SKEWNESS AND KURTOSIS FOR EACH OF THE THREE HOSPITALS

\begin{tabular}{|c|c|c|c|c|c|c|c|}
\hline VARIABLE & $M$ & $S D$ & $N$ & MIN & MAX & SKEWNESS & KURTOSIS \\
\hline \multicolumn{8}{|l|}{ Q12_MEAN } \\
\hline HOSPITAL 1 & 4.04 & 0.21 & 28 & 3.42 & 4.42 & -0.63 & 1.09 \\
\hline HOSPITAL 2 & 3.60 & 0.46 & 28 & 2.42 & 4.25 & -0.81 & 0.29 \\
\hline HOSPITAL 3 & 3.66 & 0.70 & 28 & 2.25 & 4.75 & -0.38 & -0.87 \\
\hline \multicolumn{8}{|c|}{ TRANSFORMATIONAL } \\
\hline HOSPITAL 1 & 3.01 & 0.24 & 28 & 2.55 & 3.90 & 1.36 & 4.94 \\
\hline HOSPITAL 2 & 2.38 & 0.46 & 28 & 1.60 & 3.20 & -0.16 & -1.14 \\
\hline HOSPITAL 3 & 2.33 & 0.73 & 28 & 1.10 & 3.55 & -0.28 & -1.28 \\
\hline \multicolumn{8}{|c|}{ TRANSACTIONAL } \\
\hline HOSPITAL 1 & 2.77 & 0.41 & 28 & 1.38 & 3.38 & -1.28 & 2.85 \\
\hline HOSPITAL 2 & 2.47 & 0.61 & 28 & 1.50 & 3.88 & 0.46 & -0.27 \\
\hline HOSPITAL 3 & 2.58 & 0.71 & 28 & 1.38 & 3.88 & -0.22 & -0.87 \\
\hline
\end{tabular}


HOSPITAL 1

HOSPITAL 2

Note. ${ }^{* 1}$ denotes the sample size is too small to calculate statistic.

TABLE 3. TRANSFORMATIONAL LEADERSHIP RATIO AND INTERVAL VARIABLES

\begin{tabular}{llllllll}
\hline VARIABLE & $\mathbf{M}$ & SD & $\mathbf{N}$ & MIN & MAX & SKEWNESS & KURTOSIS \\
\hline IDEALIZED ATTRIBUTES & 2.68 & 0.71 & 84 & 0.75 & 4.00 & -0.53 & -0.26 \\
IDEALIZED BEHAVIOURS & 2.76 & 0.69 & 84 & 0.25 & 4.00 & -1.29 & 2.69 \\
INDIVIDUAL CONSIDERATION & 2.05 & 0.77 & 84 & 0.00 & 4.00 & -0.45 & 0.11 \\
INSPIRATIONAL MOTIVATION & 3.00 & 0.62 & 84 & 1.25 & 4.00 & -0.90 & 0.01 \\
INTELLECTUAL STIMULATION & 2.38 & 0.83 & 84 & 0.00 & 4.00 & -0.68 & 0.02 \\
TRANSFORMATIONAL & 2.57 & 0.60 & 84 & 1.10 & 3.90 & -0.72 & -0.27 \\
\hline
\end{tabular}

Note. ${ }^{\prime * 1}$ denotes the sample size is too small to calculate statistic.

TABLE 4. Q12_MEAN, TRANSFORMATIONAL, TRANSACTIONAL AND PASSIVE AVOIDANT PEARSON CORRELATION MATRIX

\begin{tabular}{llll}
\hline VARIABLE & $\mathbf{1 .}$ & $\mathbf{2}$ & $\mathbf{3 .}$ \\
\hline 1. Q12_MEAN & - & & \\
2. TRANSFORMATIONAL & $0.57^{* *}$ & - & - \\
3. TRANSACTIONAL & $0.27^{*}$ & $0.46^{* *}$ & -0.19 \\
4. PASSIVE AVOIDANT & -0.17 & $-0.27^{*}$ & \\
\hline
\end{tabular}

Notes. ${ }^{*} \mathrm{p}<.05 .{ }^{* *} \mathrm{p}<.001 . \mathrm{n}=84$.

TABLE 5. TRANSFORMATIONAL, TRANSACTIONAL AND PASSIVE AVOIDANT VARIANCE INFLATION FACTORS

\begin{tabular}{lc}
\hline VARIABLE & VIF \\
\hline TRANSFORMATIONAL & 1.32 \\
TRANSACTIONAL & 1.27 \\
PASSIVE AVOIDANT & 1.09 \\
\hline
\end{tabular}


TABLE 6. TRANSFORMATIONAL, TRANSACTIONAL AND PASSIVE AVOIDANT LINEAR REGRESSION COEFFICIENTS PREDICTING Q12_MEAN

\begin{tabular}{|c|c|c|c|c|c|c|}
\hline VARIABLE & B & SE & $\mathrm{Cl}$ & B & $T$ & $P$ \\
\hline (INTERCEPT) & 2.48 & 0.29 & {$[1.90,3.05]$} & 0.00 & 8.56 & $<.001$ \\
\hline TRANSFORMATIONAL & 0.49 & 0.09 & {$[0.31,0.68]$} & 0.56 & 5.30 & $<.001$ \\
\hline TRANSACTIONAL & 0.01 & 0.09 & {$[-0.17,0.20]$} & 0.01 & 0.13 & .896 \\
\hline PASSIVE AVOIDANT & -0.01 & 0.05 & {$[-0.11,0.09]$} & -0.02 & -0.20 & .842 \\
\hline
\end{tabular}

Note. $\mathrm{Cl}$ is at the $95 \%$ confidence level. Results: $\mathrm{F}(3,80)=12.91, \mathrm{p}<.001, \mathrm{R} 2=0.33$

Unstandardized Regression Equation: Q12_Mean $=2.48+0.49 *$ Transformational $+0.01 *$ Transactional $-0.01 *$ Passive Avoidant

\section{TRANSACTIONAL LEADERSHIP}

As seen from Table 2, Hospital 1, which also had the highest transformational leadership preference, had the highest preference for transformational leadership, followed by Hospital 3 and 2, as determined by the recorded Q12_Mean values recorded for each case. The transformational leadership traits which had the highest level of preference among the population sample were found to be Contingent Reward, Transactional and Management Exception Passive, as seen in Table 7 below.

After transformational leadership, transactional leadership was seen to have the second highest Pearson Correlation Matrix among the three leadership styles being studied as illustrated in Table 4. In addition, Table 5 and 6 show that transactional leadership, compared to transformational and passive avoidant leadership, had the second highest Variance Inflation Factor and Linear Regression Coefficients.

\section{PASSIVE AVOIDANT LEADERSHIP}

According to the results collected, although to a lower extent than the other two leadership styles Hospital 2 had the highest preference for passive avoidant leadership, followed by Hospital 3 and 1 respectively. This was according to the Q12_Mean values recorded for each hospital as seen in Table 2. Furthermore, Management Exception Passive, Passive Avoidant and Laissez faire were the passive avoidant traits with the highest preference rate, as indicated by the high mean values illustrated in Table 8 below.

Compared to transformational and transactional leadership, passive avoidant leadership was seen to have the lowest Pearson Correlation Matrix, which was found to be a negative value, as illustrated in Table 4. In addition, Table 5 and 6 show that passive avoidant leadership, compared to transformational and transactional leadership, had the lowest Variance Inflation Factor and Linear Regression Coefficients.

TABLE 7. TRANSACTIONAL LEADERSHIP RATIO AND INTERVAL VARIABLES

\begin{tabular}{llllllll}
\hline VARIABLE & $\mathbf{M}$ & SD & $\mathbf{N}$ & MIN & MAX & SKEWNESS & KURTOSIS \\
\hline CONTINGENT REWARD & 2.81 & 0.75 & 84 & 1.00 & 4.00 & -0.58 & -0.29 \\
MANAGEMENT EXCEPTION ACTIVE & 2.40 & 0.65 & 84 & 0.75 & 4.00 & -0.44 & 0.45 \\
TRANSACTIONAL & 2.61 & 0.59 & 84 & 1.38 & 3.88 & -0.26 & -0.35 \\
\hline
\end{tabular}

Note. '*' denotes that the sample size was too small to calculate a statistic. 


\begin{tabular}{lccccccc}
\hline VARIABLE & $\mathbf{M}$ & SD & $\mathbf{N}$ & MIN & MAX & SKEWNESS & KURTOSIS \\
\hline LAISSEZ FAIRE & 1.34 & 1.21 & 84 & 0.00 & 4.00 & 0.61 & -0.90 \\
MANAGEMENT EXCEPTION PASSIVE & 1.57 & 0.96 & 84 & 0.00 & 3.75 & 0.48 & -0.71 \\
PASSIVE AVOIDANT & 1.45 & 1.02 & 84 & 0.00 & 3.62 & 0.69 & -0.83 \\
\hline
\end{tabular}

Note. '*' denotes that the sample size was too small to calculate a statistic.

\section{DISCUSSION AND CONCLUSIONS}

\section{TRANSFORMATIONAL LEADERSHIP}

As previously described, transformational leadership utilises individual consideration and the stimulation of charisma and intellectual senses for the purpose of achieving set goals. [23] As such, transformational leadership involves the application of various mechanisms for improving organisational output by enhancing employee motivation, performance and morale. [24] According to the collected results, transformational leadership had the overall highest preference rate in Hospital 1, as indicated by the recorded Q12_Mean value which was the highest value among the three leadership styles being studied. This shows the overall high rate of preference for transformational leadership among health workers from these particular categories. The mean for Hospital 1 also establishes that transformational leadership is the most preferred leadership style within the population sample.

Moreover, the Variance Inflation Factor recorded for transformational leadership was the overall highest value among the three leadership styles. This finding implies a high-level impact exists between transformational leadership and employee engagement, highlighting a positive relationship between the two variables. This relationship could be a result of high leader-follower interaction portrayed through transformational leadership, which facilitates efficient communication between parties. Effective communication bears significant importance within the health sector through its facilitation of easy issue identification due to employees communicating suggestions, requests and grievances to managers. [24] Consequently, transformational leadership, through enhancing effective communication, significantly contributes to developing problem-solving initiatives for issues identified as interfering with effective employee performance. Solving such issues in turn helps improve employee engagement levels, resulting in improved patient outcomes.

Further support for the positive relationship between transformational leadership and employee engagement was illustrated by the 0.57 correlation coefficient, suggesting a significant effect between the leadership styles and the Q12_Mean. Moreover, a moderate size correlation coefficient of 0.46 was observed between transformational and transactional leadership, implying a positive relationship. This finding also implies that, since an increase in transformational leadership styles results in increased employee engagement, an increase in transactional leadership would yield the same result. Consequently, the overall highest positive correlation with Q12_Mean, VIF and overall preference rate portrayed by transformational leadership highlights the need to utilise this style of leadership in the PNG health sector to achieve increased employee engagement. As such, the null hypothesis of the first research question, which highlighted the absence of a positive relationship between engagement among healthcare employees and transformational leadership techniques, was rejected in favour of the alternate hypothesis, which highlighted a positive relationship.

\section{TRANSACTIONAL LEADERSHIP}

Transactional leadership revolves around irregularity-based management, whereby leaders get involved in employee management only when irregularities occur. [25] As such, employees are motivated to achieve set goals through a contingency reward system which ensures successful employees are rewarded, while those who fail are punished. [16] According to the collected results, this leadership style had the overall second highest preference rate among the three hospitals, with Hospital 1 having the highest preference for transactional leadership, followed 
by Hospital 3. These findings show the high preference rate of transactional leadership within the specific health worker divisions and departments recorded for each case, implying increased engagement upon its utilisation.

A high preference rate for transactional leadership was also illustrated by the calculated VIF value, which was the second highest among the three leadership techniques. This high preference rate would be a result of a contingency reward system involved during the implementation of transactional leadership, which is a major facilitator of increased employee engagement, as a result of the associated motivation. Thus, a positive relationship exists between transactional leadership and employee engagement.

The small positive relationship has also been highlighted by the existence of a moderate positive correlation coefficient of 0.27 between transactional leadership and the Q12_Mean, indicating that an increase in transactional leadership would yield increased engagement levels within the PNG health sector. This relationship is further cemented by the existence of a positive correlation between transactional and transformational leadership, as previously mentioned, which indicates that the application of both leadership styles results in improved engagement levels among healthcare workers. A positive relationship was also discovered between transactional leadership and employee engagement, showing that increased application of transactional leadership styles would increase employee engagement in the PNG health sector. Consequently, the null hypothesis of the second research question, which highlighted the absence of a positive relationship between employee engagement among healthcare employees and transactional leadership techniques, was rejected in favour of the alternate hypothesis, which highlighted a positive relationship.

\section{PASSIVE AVOIDANT LEADERSHIP}

Passive avoidant leadership revolves around leaders' intentional avoidance of involvement in employee organisation. [26] In contrast to transformational and transactional leadership, this style bears the highest degree of passive management, which implies the existence of a low level of leader-follower interaction. According to collected results, Hospital 2 had the highest overall preference rate for passive avoidant leadership styles. Although a high preference rate was recorded within this hospital, passive avoidant leadership style still had the lowest overall preference among the three hospitals.
The low preference was further highlighted by the VIF value calculated from the collected data, which was the lowest for the three leadership techniques, implying that a negative relationship exists between passive avoidant leadership and employee engagement. The negative relationship was also illustrated by the negative small size correlation coefficient of -0.27 between passive avoidant leadership and the Q12_Mean, portraying the negative effect this leadership style has on employee engagement. This negative relationship may directly result from the absence of leader-follower interactions in passive avoidant leadership, which ultimately reduces motivation and satisfaction levels among employees within the highstress environment in the health sector.

Additionally, the low preference and negative correlation with the Q12_Mean imply that passive avoidant leadership styles negatively affect employee engagement levels, such that the increased application of this leadership style leads to reduced engagement levels. Therefore, in order to yield an increase in employee engagement levels in the PNG health sector, the application of passive avoidant leadership styles should be avoided. Consequently, the null hypothesis of the third research question, which highlighted the absence of a positive relationship between employee engagement among healthcare employees and passive avoidant leadership techniques, was not rejected, while the alternate hypothesis, which highlighted a positive relationship, was rejected.

This research aimed to examine the relationship between employee engagement and three leadership stylestransformational, transactional and passive avoidant-in the PNG health sector. Although this study had the limitations of time constraints, lack of control over the environment and shift variability, strengths such as population validity and convenient data gathering facilitated the collection of data for accurate analysis. Consequently, accurate analysis of the collected data enabled a critical examination of the nature of the relationship between employee engagement and leadership styles. More specifically, while the results revealed a positive relationship between both transformational and transactional leadership styles and employee engagement in the PNG health sector, a negative relationship was revealed between passive avoidant leadership and employee engagement. Consequently, this finding facilitated the rejection of the null hypotheses of the first two research questions, which highlighted the absence of a positive relationship between 
employee engagement and transformational and transactional leadership in the PNG health sector. Moreover, the collected results led to a failure to reject the third null hypothesis, which highlighted the absence of a positive relationship between passive avoidant leadership and employee engagement in the PNG health sector. As such, in light of the aforementioned strengths these results portrayed some disparity to Huang et al.'s [26] findings, which highlighted the importance of workplace safety climate as the overall determinant of employee engagement levels. Although safety climate can be considered as a major influencing factor of engagement levels, findings collected during this study portrayed leadership style as the most significant influencing factor on employee engagement.

While findings obtained during this study illustrate the implications of increased utilisation of transformational and transactional leadership styles, reduced utilisation of passive avoidant leadership in the PNG health sector in order to yield increased engagement levels has also been illustrated. Regardless of limitations caused by the total reliance of quantitative analysis on numerical indicators and the small size of the population sample compared to the overall population of health workers in PNG, results obtained during the course of this study still possess a high degree of statistical relevance.

Ultimately, these findings provide a strong foundation for conducting future academic research on employee engagement in the PNG health sector. In addition, managerial implications of this study would facilitate the establishment of improved managerial structures within the health sector through the implementation of effective leadership techniques for the purpose of improving patient outcomes as a direct result of increased engagement levels. Such improvements would in turn aid in the development of healthcare management policies that combine leadership styles which positively impact employee engagement, leading to the overall advancement of healthcare service provision in developing countries. Through further research on the relationship between engagement and effective leadership in future studies, health care advancement may feature a higher degree of sustainability, which may enable the continued provision of high quality services in spite of future challenges arising not only from the evergrowing demand for health care, but also the issue of unequal distribution of resources which occurs in many developing countries.

\section{References}

1. Musinguzi C, Namale L, Rutebemberwa E, Dahal A, Nahirya-Ntege P, Kekitiinwa A. The relationship between leadership style and health worker motivation, job satisfaction, and teamwork in Uganda. J Healthc Leadersh 2018; 10:21-32.

2. Okello DR, Gilson L. Exploring the influence of trust relationships on motivation in the health sector: a systematic review. Hum Resour Health 2015;13(1):1-18.

3. Ashwell HE, Barclay L. Problems measuring community health status at a local level: Papua New Guinea's health information system. Rural Remote Health 2010;10(4): Article 1539. Available: <https://www.rrh.org.au/journal/article/1539> (Accessed 24/05/20)

4. Cairns A, Witter S, Hou X. (2018). Exploring factors driving the performance of rural health care in Papua New Guinea [Policy note]. Available from: <https://openknowledge.worldbank.org/handle/1098 6/29875> (Accessed 24/05/20)

5. Razee $H$, Whittaker M, Jayasuriya R, Yap L, Brentnall L. Listening to the rural health workers in Papua New Guinea-the social factors that influence their motivation to work. Soc Sci Med 2012;75(5):828-835.

6. Giltinane CL. Leadership styles and theories. Nurs Stand 2013;27(41):35-39.

7. McCleskey JA. Situational, transformational, and transactional leadership and leadership development. Journal of Business Studies Quarterly 2014;5(4):117-130.

8. Chaudhry AQ, Javed $\mathrm{H}$. Impact of transactional and laissez faire leadership style on motivation. International Journal of Business and Social Science 2012;3(7):258-264.

9. Lowe G. How employee engagement matters for hospital performance. Healthc Q 2012;15(2):29-39.

10. Ambang T. Implementation of the National Health Plan in the PNG decentralised health system. Contemporary PNG Studies. 2015 May; 22:105.

11. Tyczkowski B, Vandenhouten C, Reilly J, Bansal G, Kubsch SM, Jakkola R. Emotional intelligence (EI) and nursing leadership styles among nurse managers. Nurs Adm Q 2015; 39(2):172-180

12. Xenikou, A. (2017). Transformational leadership, transactional contingent reward, and 
organizational identification: The mediating effect of perceived innovation and goal culture orientations.

Frontiers in Psychology, 8.

doi:10.3389/fpsyg.2017.01754

13. Batista-Taran LC, Shuck MB, Gutierrez CC, Baralt S. The role of leadership style in employee engagement. In: MS Plakhotnik, SM Nielsen, DM Pane. Proceedings of the Eighth Annual College of Education and Graduate Student Network Research Conference (pp. 15-20). Miami, FL: Florida International University; 2013.

14. Hutchinson, M., \& Jackson, D. (2013). Transformational leadership in nursing: Towards a more critical interpretation. Nursing Inquiry, 20(1), 11-22. https://doi.org/10.1111/nin.12006

15. Neuman WL, Wiegand B. Criminal justice research methods: qualitative and quantitative approaches. National Criminal Justice Reference Service; 2011.

16. Gay L, Mills G, Airasian P. Educational research competencies for analysis and applications (8th ed.). Hoboken, NJ: Pearson; 2006.

17. Patel VM, Ashrafian H, Uzoho C, Nikiteas N, Panzarasa $P$, Sevdalis N, Darzi A, Athanasiou T. Leadership behaviours and healthcare research performance: prospective correlational study. Postgrad Med J 2016:92(1093):663-669.

18. Osborne J, Waters E. Four assumptions of multiple regression that researchers should always test. Pract. Assess. Res. Evaluation 2002;8(2):1-9.

19. Avolio, B. J., \& Bass, B. M. (2004). Multifactor leadership questionnaire (MLQ). Mind Garden, 29.

20. Neuman WL. Basics of social research: qualitative and quantitative approaches. Boston: Pearson/Allyn and Bacon; 2007.

21. Durrheim K. Research design. In: M Terre Blanche, $K$ Durrheim. Research in practice: applied methods for the social sciences. Cape Town: University of Cape Town Press; 2002.

22. Bass, B., \& Avolio, B. (1995). MLQ Multifactor leadership questionnaire. Redwood City, CA: Mind Garden

23. Hoch JE, Bommer WH, Dulebohn JH, Wu D. Do ethical, authentic, and servant leadership explain variance above and beyond transformational leadership? A meta-analysis. J Manage 2018;44(2): 501-529.

24. Saravo B, Netzel J, Kiesewetter J. The need for strong clinical leaders-transformational and transactional leadership as a framework for resident leadership training. PloS One 2017;12(8). Available: <doi: 10.1371/journal.pone.0183019> (Accessed 24/05/20)

25. Aga DA. Transactional leadership and project success: the moderating role of goal clarity. Procedia Comput Sci 2016; 100:517-525.

26. Huang, Y. H., Lee, J., McFadden, A. C., Murphy, L. A., Robertson, M. M., Cheung, J. H., \& Zohar, D. (2016). Beyond safety outcomes: An investigation of the impact of safety climate on job satisfaction, employee engagement and turnover using social exchange theory as the theoretical framework. Applied ergonomics, 55, 248-257. 